\title{
Media Sistem Peredaran Darah Hewan dan Manusia Dilengkapi Augmented Reality Kelas V Sekolah Dasar
}

\author{
Leny Suryaning Astutik ${ }^{1}$, Markus Diantoro ${ }^{2}$, Sentot Kusairi ${ }^{2}$ \\ ${ }^{1}$ Pendidikan Dasar-Universitas Negeri Malang \\ ${ }^{2}$ Pendidikan Fisika-Universitas Negeri Malang
}

\begin{tabular}{l}
\hline \hline INFO ARTIKEL \\
\hline Riwayat Artikel: \\
Diterima: $22-05-2020$ \\
Disetujui: $19-12-2020$ \\
\hline
\end{tabular}

\section{Kata kunci:}

augmented reality; learning media;

bloodstream system;

augmented reality;

media pembelajaran;

sistem peredaran darah

\begin{abstract}
ABSTRAK
Abstract: The circulatory system and animals are important materials to learn in elementary school. The purpose of this study is to produce SIPERDA media equipped with augmented reality for the fifth grade of Malang Regency Primary School which is effective, valid, and practical. The development of SIPERDA uses the ADDIE model. The results showed the average for validity from media experts, material experts, and learning experts was $87.2 \%$ with the category "Very Valid". Practicality gained from small-scale student responses, small-scale teacher responses, large-scale student responses, large-scale teacher responses by $88 \%$ with the category "Very Practical". Whereas the effectiveness is obtained from the average value of the experimental class of 89 and the control class of 83. In addition, the increase in learning outcomes is tested using Ancova which can increase the effective media used.
\end{abstract}

\begin{abstract}
Abstrak: Sistem peredaran darah dan hewan merupakan bahan yang penting untuk dipelajari di Sekolah Dasar. Tujuan penelitian ini adalah untuk menghasilkan media SIPERDA dilengkapi augmented reality untuk kelas lima Sekolah Dasar Kabupaten Malang yang efektif, valid, dan praktis. Pengembangan SIPERDA ini menggunakan model ADDIE. Hasil penelitian menunjukkan rata-rata untuk kevalidan dari pakar media, ahli materi, dan pakar pembelajaran sebesar $87.2 \%$ dengan kategori "Sangat Valid". Kepraktisan yang didapat dari respon siswa skala kecil, respon guru skala kecil, respon siswa skala besar, respon guru skala besar sebesar $88 \%$ dengan kategori "Sangat Praktis". Sementara itu, untuk keefektifan diperoleh dari nilai rata-rata kelas eksperimen (Island) sebesar 89 dan kelas control (Ocean) sebesar 83. Selain itu, peningkatan hasil belajar diuji menggunakan Ancova yang dapat meningkatkan media yang efektif digunakan.
\end{abstract}

\section{Alamat Korespondensi:}

Leny Suryaning Astutik

Pendidikan Dasar

Universitas Negeri Malang

Jalan Semarang 5 Malang

E-mail: lennyshadenley@ gmail.com

Pentingnya IPA diberikan sejak usia sekolah dasar yaitu pendidikan ilmu alam dasar adalah membuat anak-anak mengamati, menyelidiki alam, belajar membedakan hubungan antara fakta dan fenomena, merasakan integritas dunia di lingkungan sekitarnya (Lamanauskas, 2009), (Juniati \& Widiana, 2017). IPA di kelas V Sekolah Dasar siswa mempelajari tentang sistem peredaran darah. Materi ini sulit dipelajari secara langsung, tetapi dapat dipermudah dalam mempelajari dengan memanfaatkan media yang membantu menstimulus siswa menyerap materi pembelajaran dengan optimal (Fajar, 2016), (Subekti, 2017). Berdasarkan bukti hasil wawancara pada tanggal 1 Juli 2019 di SD Unggulan Permata Jingga dengan ibu Ririn Rochmawati S.Si terdapat beberapa kendala dari siswa, di antaranya (1) minat terhadap mata pelajaran IPA, (2) materi sulit dilihat secara langsung, dan (3) sumber belajar siswa yang terbatas pada buku guru, buku siswa, video dari YouTube (satu arah) dan gambar di dinding. Sementara itu, faktor yang dipengaruhi guru, meliputi (1) guru mengajar menggunakan metode ceramah dan tanya jawab (konvensional), (2) kurangnya intensitas penggunaan media elektronik yang mendukung proses pembelajaran, dan (3) guru terlalu sibuk dan hanya memanfaatkan tool yang disediakan sekolah.

Berdasarkan bukti hasil analisis kebutuhan guru pada tanggal 22 Agustus 2019 Kelas V menyatakan bahwa siswa kesulitan dalam menyerap materi khusunya materi sistem peredaran darah hewan dan manusia. Selain itu, siswa lebih mudah menerima materi dengan media berbasis teknologi. Guru sudah berusaha menghadirkan media video, gambar, alat peraga organ manusia akan tetapi kurang efektif dikarenakan sering rusak serta harga untuk media alat peraga relatif mahal. Berdasarkan kondisi di lapangan, rata-rata umur siswa kelas V sekitar 7-11 tahun memiliki ciri rasa ingin tahu yang besar, senang bermain dan cara berpikir terstruktur (Ardini, 2012). 
Berdasarkan bukti hasil observasi dan pengamatan pembelajaran, fasilitas di dalam kelas, meliputi (1) media gambar sistem peredaran darah hewan dan manusia, (2) papan tulis menggunakan whiteboard, (3) laptop, Liquid Crystal Display (LCD) dan proyektor, (4) akses internet di seluruh area sekolah, tetapi sedikit lambat pada kelas-kelas tertentu. Beberapa fasilitas tersebut dapat dimanfaatkan untuk membuat atau mengembangkan media berbasis teknologi untuk mempermudah penyampaian konsep materi, khususnya sistem peredaran darah hewan dan manusia (Tambayong, Lumenta, \& Sugiarso, 2016).

Media berperan penting dalam pembelajaran selain materi, tujuan, metode dan evaluasi (Falahudin, 2014), (So, Chen, \& Wan, 2019). Media pembelajaran khususnya untuk mata pelajaran IPA memiliki manfaat diantaranya mampu keterbatasan daya indera seperti objek terlalu kecil atau besar, mengurangi verbal, mengatasi keterbatasan waktu, dan ruang (Astutik, 2019). Media memiliki berbagai jenis ada media modern, tradisional, visual, audio, kinestetik, proyeksi, media non proyeksi, dan jenis lainnya (Astutik, 2016). Hasil belajar siswa bisa meningkat dengan memperhatikan media yang digunakan (Khotimah \& Ardian, 2017).

Hasil belajar adalah pernyataan luas tentang apa yang dicapai dan dinilai pada akhir mata pelajaran (Harden, 2002). Hasil belajar memiliki lima, meliputi (a) intelektual, (b) verbal, (c) kognitif, (d) sikap, dan (e) motorik (Gagne, 1984). Faktor diri sendiri dan faktor alam, sarana, prasarana, faktor masyarakat, faktor keluarga, dan faktor psikologis dapat memengaruhi hasil belajar (Mappeasse, 2009). Hasil belajar tidak serta merta menilai siswa, tetapi dapat digunakan sebagai perbaikan program yang dijalankan sekolah (Baharun, 2015). Pemanfaatan media augmented reality yang benar akan berdampak pada hasil belajar yang tinggi karena dapat memproyeksikan benda-benda virtual (Bagus, Buchori, \& Aini, 2018).

Teknologi augmented reality merupakan teknologi yang mampu membuat gambar tiruan tiga dimensi dengan cara menggabungkan objek nyata dengan virtual sehingga memiliki kemiripan dengan objek sesungguhnya (Liarokapis et al., 2004), (Gonydjaja \& Mayongga, 2014), (Liberati, 2016). Manfaat augmented reality ini juga memberikan peluang besar dalam Ilmu Pengetahuan Alam karena menekankan pada pelatihan secara langsung (real time) dan praktis (Cheng, 2018). Bahkan ada badan penelitian yang berkaitan dengan augmented reality (AR) yang digunakan untuk belajar di sektor pendidikan dasar dan menengah di seluruh dunia (Pellas, Fotaris, Kazanidis, \& Wells, 2018). Sekarang telah dikembangkan sebagai inovasi pembelajaran di Indonesia. Sebagai contoh, penelitian yang dilakukan oleh Ou mengembangkan augmented reality seabagai solusi terhadap masalah pemahaman konsep fase bulan (Tarng, Lin, Lin, \& Ou, 2016). Augmented reality mampu mengatasi kendala belajar siswa untuk mata pelajaran IPA (Saputri, Annisa, \& Kusnandi, 2018). Augmented reality mampu memberikan gambaran yang lebih konkret di bandingkan dengan metode pembelajaran konvensional (ceramah) (Yoon, Anderson, Lin, \& Elinich, 2017), (Khan, Johnston, \& Ophoff, 2019).

Pengembangan media dilengkapi augmented reality ini merupakan suatu cara untuk mengenalkan teknologi dan mempermudah memahami sistem peredaran darah hewan dan manusia. Pengembangan media dilengkapi augmented reality dapat meningkatkan hasil belajar yang relevan dengan penelitian (Chiang, Yang, \& Hwang, 2014), (Sartika, Tambunan, \& Telnoni, 2016). Selain itu selaras dengan penelitian (Laine, Nygren, \& Dirin, 2016) bahwa augmented reality layak digunakan di Sekolah Dasar. Konsep ilmiah yang abstrak bisa dijabarkan menggunakan augmented reality dengan cara yang menarik, menyenangkan, memungkinkan pembelajaran sains dimana saja dan kapan saja melalui pengalaman pembelajaran kontekstual. Hasil penelitian (Saputri et al., 2018) pengembangan media dilengkapi augmented reality memperoleh nilai dari ahli media, ahli materi, ahli pembelajaran, respons siswa secara berturut-turut 90.6\%, 96\%, 92.6\% dan 91.6\%. Augmented reality juga dapat meningkatkan prestasi siswa, kemampuan belajar mandiri, juga memastikan bahwa tingkat pengendalian diri siswa meningkat, keterampilan pemecahan masalah serta augmented reality lebih baik dibandingkan pembelajaran dengan metode ceramah, (Karagozlu, 2018), (Papanastasiou, Drigas, Skianis, Lytras, \& Papanastasiou, 2019), (Cakir \& Korkmaz, 2019).

Berdasarkan pemaparan penelitian diatas banyak saran agar peneliti selanjutnya mengembangkan fitur dalam media berbasis augmented reality dan pengembangan materi. Berdasarkan hasil wawancara, observasi, studi literatur, analisis kebutuhan dapat ditarik kesimpulan bahwasannya (1) pemanfaatan media untuk materi sistem peredaran darah hewan dan manusia belum optimal, (2) fasilitas yang menunjang untuk dihadirkannya inovasi media yang digunakan dalam pembelajaran dengan augmented reality, (3) pembelajaran dengan memanfaatkan augmented reality memiliki beragam manfaat seperti menarik, menyenangkan, membuat visualisasi lebih nyata dengan waktu real time. Media SIPERDA dilengkapi augmented reality dikembangkan didasarkan pada kebutuhan untuk mendukung kegiatan pembelajaran, karakteristik siswa dan kesesuaian dengan perkembangan zaman.

\section{METODE}

Model penelitian dan pengembangan ini menggunakan model ADDIE. ADDIE memiliki lima tahapan utama, yaitu Analysis-Design-Develop-Implement-Evaluate. Alasan menggunakan model ADDIE adalah (1) memiliki langkah pengembangan yang jelas, (2) bersifat deskriptif, (3) terstruktur dan sistematis, (4) setiap tahapan dari model $A D D I E$ terdapat revisi maupun evaluasi. Pengembangan model ADDIE dimulai dengan tahap analisis yang mencangkup analisis kebutuhan, analisis kurikulum. Tahap design menyusun kisi-kisi instrumen, membuat prototype produk dan membuat soal. Tahap develop yaitu dengan membuat media, buku petunjuk, validasi, dan revisi. Tahap implement dilakukan di SD Unggulan Permata Jingga Malang dengan menggunakan subjek kelas V Sekolah Dasar. Subjek dibagi menjadi dua bagian skala besar total siswa berjumlah 40 orang dan skala kecil empat orang. Implementasi media siswa di kelas IV Island sebagai kelas eksperimen dibelajarkan menggunakan pembelajaran media SIPERDA dilengkapi augmented reality dan siswa di kelas V Ocean sebagai 
kelas kontrol dibelajarkan dengan pembelajaran yang biasa dilakukan guru tanpa menggunakan media pembelajaran (sumber belajar buku). Penelitian ini dilaksanakan sebanyak tiga kali pertemuan yang dilakukan secara terpisah bertempat di laboratorium komputer.

Data dari hasil validasi ahli dan kepraktisan yang diperoleh dari respon siswa maupun guru akan dianalisis secara kuantitafif maupun kualitatif. Data berupa saran, komentar, masukan perbaikan dari ahli, maupun respon guru akan dianalisis secara kualitatif. Sedangkan berupa data nilai, skor akan dianalisis secara kuantitatif. Sedangkan data hasil belajar adalah hasil yang akan digunakan menentukan keefektifan. Keefektifan dilihat dari skor postest dan Pretest siswa. Hasil keefektifan akan di uji menggunakan uji ancova dengan memenuhi prasarat homogen dan normalitas. (1) uji normalitas melalui uji kolmogorovsmirnov. Data dapat dinyatakan normal apabila Sig. > 0,05. (2) uji homogen varian (digunakan agar diketahui perbedaan varian data masing-masing kelas eksperimen) melalui uji Levene's Test. Data dikatakan homogen apabila P > 0,05. Jika syarat sudah memenuhi dilanjutkan dengan menguji hipotesis. Hipotesis penelitian menggunakan analisis kovarian (ancova) dengan menggunakan program SPSS 21 dengan $\alpha=0,05$.

\section{HASIL}

Media SIPERDA merupakan produk hasil pengembangan yang dilengkapi dengan buku petunjuk SIPERDA. Media SIPERDA divalidasi oleh beberapa ahli. Berikut ini dapat dijabarkan data tingkat kevalidan media SIPERDA dilengkapi augmented reality.

Tabel 1. Hasil Kevalidan SIPERDA

\begin{tabular}{clccl}
\hline No. & Tahapan Penelitian & Jumlah Skor & Persentase & Kriteria \\
\hline 1. & Ahli Media & 131 & $84.5 \%$ & Sangat Valid \\
2. & Ahli Materi & 85 & $84.7 \%$ & Sangat Valid \\
3. & Ahli Pembelajaran & 111 & $92.5 \%$ & Sangat Valid \\
\hline \multicolumn{2}{c}{ Rata-rata } & 109 & $87.2 \%$ & Sangat Valid \\
\hline
\end{tabular}

(Sumber: Peneliti, 2019)

Berdasarkan hasil tanggapan dari ahli terdapat beberapa masukan maupun saran yang dapat digunakan untuk memperbaiki media SIPERDA, meliputi (1) cover sebaiknya dibuat ada essensi hewan dan manusia, (2) perlu disempurnakan struktur jawaban dalam soal evaluasi, dan (3) dibuat versi ringan dan terhubung internet.

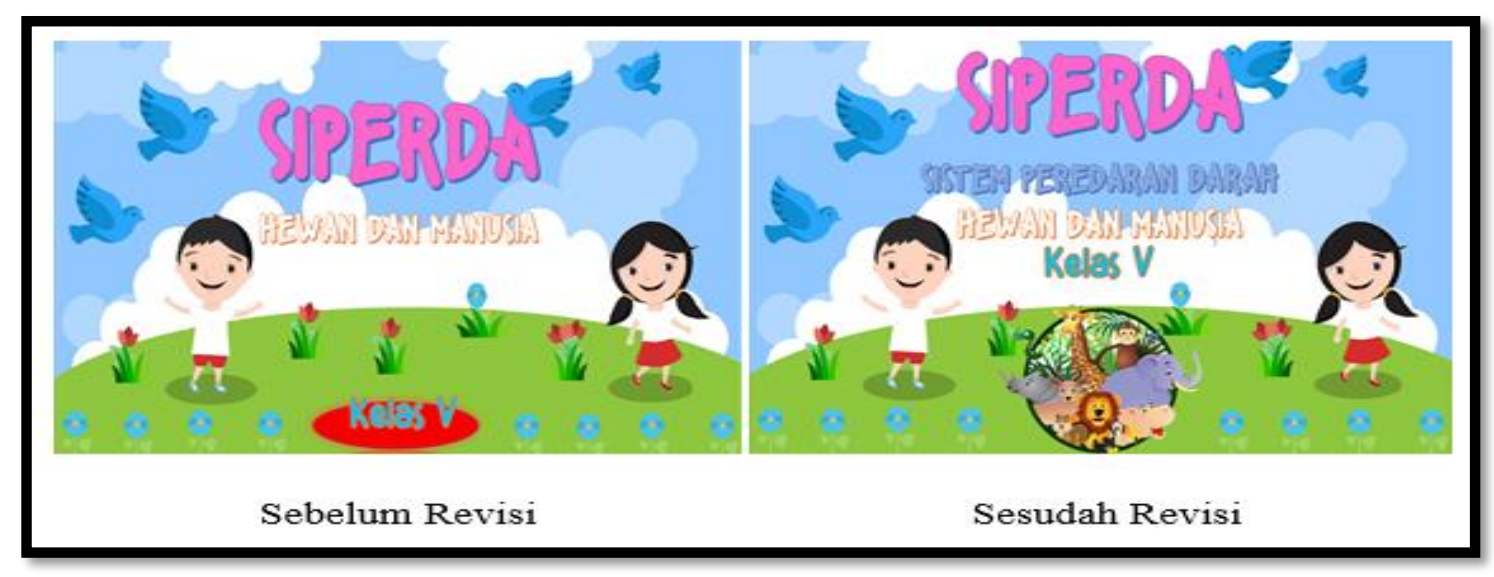

Gambar 1. Revisi Media SIPERDA Berdasarkan Saran Ahli Media 


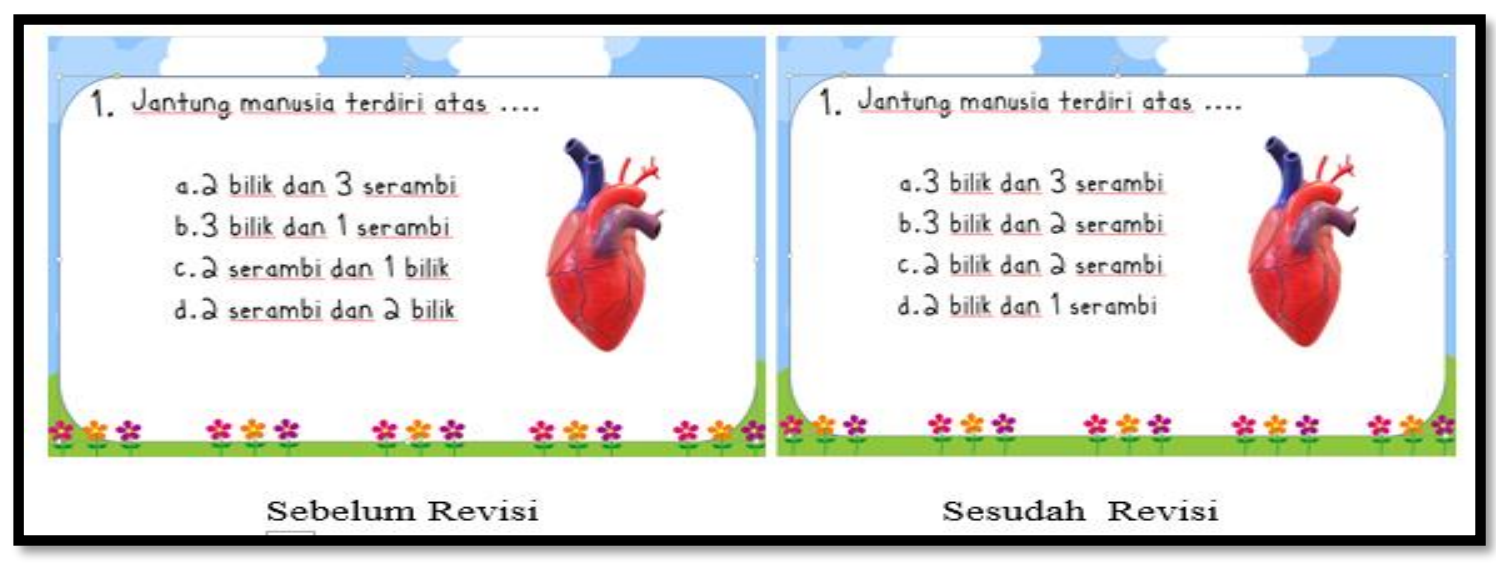

Gambar 2. Revisi Media SIPERDA Berdasarkan Saran Ahli Materi

Kepraktisan media dari penelitian ini diambil dari respon siswa dan guru ketika uji coba baik skala kecil maupun besar. Hal ini digunakan untuk menarik data bahwasanya media SIPERDA memudahkan siswa. Aspek yang diajukan untuk dinilai melalui media SIPERDA meliputi tampilan dan materi. Hasil untuk angket respons siswa dan guru ditunjukkan pada tabel 2.

Tabel 2. Hasil Kepraktisan Media SIPERDA

\begin{tabular}{ccccc}
\hline No. & Tahapan Penelitian & Jumlah Skor & Persentase & Kriteria \\
\hline 1. & Respon Siswa Skala Kecil & 74 & $88 \%$ & Sangat Praktis \\
2. & Respon Guru Skala Kecil & 48 & $87.2 \%$ & Sangat Praktis \\
3. & Respon Siswa Skala Besar & 243 & $82.5 \%$ & Sangat Praktis \\
4. & Respon Guru Skala Besar & 52 & $94.5 \%$ & Sangat Praktis \\
\hline \multicolumn{6}{c}{ Rata-rata } & 417 & $88 \%$ & Sangat Praktis \\
\hline
\end{tabular}

(Sumber: Peneliti, 2019)

Keefektifan pada penelitian ini dilihat dari kenaikan skor pretest dan posttest dari kelas Ocean maupun kelas Island. Berikut hasil kenaikan posttest dan pretest pada tabel 3.

Tabel 3. Hasil Kelas Ocean dan Kelas Island

\begin{tabular}{cccccc}
\hline Nama & Pretest & Posttest & Nama & Pretest & Posttest \\
\hline Ocean & & \multicolumn{2}{c}{ Island } & \\
\hline AEA & 66 & 72 & ABIS & 61 & 89 \\
ANS & 72 & 89 & ALP & 72 & 100 \\
DAP & 72 & 89 & ESA & 50 & 77 \\
FEB & 61 & 89 & FS & 66 & 89 \\
GHAG & 72 & 89 & GAJMA & 55 & 89 \\
HHA & 55 & 72 & ISP & 72 & 89 \\
KIEP & 61 & 72 & KNAW & 72 & 100 \\
KAK & 50 & 89 & KSI & 61 & 83 \\
LPP & 72 & 72 & M & 66 & 83 \\
LA & 66 & 89 & MAV & 50 & 83 \\
MLA & 55 & 72 & RA & 66 & 94 \\
NMSA & 61 & 100 & TJ & 50 & 83 \\
NKA & 50 & 72 & ZN & 72 & 94 \\
SAKP & 72 & 89 & MKFH & 55 & 89 \\
\hline Rata-rata & 63 & 83 & Rata-rata & 62 & 89 \\
\hline
\end{tabular}

(Sumber: Peneliti, 2019)

Berdasarkan data diatas maka langkah selanjutnya dilakukan pengujian normalitas dan homogenitas. Hasil uji normalitas pada tabel 4 dan uji homogen pada tabel 5 . 
Tabel 4. Hasil Uji Normalitas

\begin{tabular}{lr}
\hline Asymp. Sig, (2-tailed) \\
\hline
\end{tabular}

(Sumber: SPSS 21)

Tabel 5. Hasil Uji Homogen

\begin{tabular}{lllll}
\hline & Levene Statistic & dF1 & dF2 & Sig. \\
\hline Pretest & .570 & 1 & 26 & .813 \\
Posttest & 8.182 & 1 & 26 & .062 \\
\hline
\end{tabular}

(Sumber: SPSS 21)

Tabel 4 menyatakan bahwa nilai signifikansi (Sig) untuk keseluruhan data hasil belajar siswa .616>0,05, sehingga dapat diambil kesimpulan data tersebut terdistribusi normal. Tabel 5 menunjukkan nilai signifikansi untuk data pretest sebesar 0,813 dan posttest sebesar 0,062. Hasil menunjukkan bahwa nilai signifikansi data hasil belajar siswa > dari Sig. (0,05) sehingga data homogen. Data hasil belajar siswa memenuhi uji prasyarat maka dapat dilakukan uji ancova. Hasil uji ancova ditunjukkan pada tabel 6.

Tabel 6. Hasil Uji Ancova

\begin{tabular}{cccccc}
\hline Source & Type III Sum of Squares & Df & Mean Square & F & Sig. \\
\hline Kelas & 320.295 & 1 & 320.295 & 5.599 & 0.026 \\
\hline
\end{tabular}

\section{(Sumber: SPSS 21)}

Berdasarkan hasil analisis data menggunakan ancova didapatkan nilai signifikansi untuk kelas dengan Pretest sebagai kovariat adalah $0.026<0.05$ sehingga ada perbedaan antara yang mengikuti pembelajaran menggunakan media SIPERDA dengan pembelajaran tanpa menggunakan media SIPERDA.

\section{PEMBAHASAN}

Pada penelitian ini setelah dilakukan validasi kepada ahli media didapatkan skor 131 dari total skor maksimal 155. Jumlah pernyataan yang diberikan kepada ahli sejumlah 31 butir pernyataan. Pada angket yang telah diberikan ahli media memberikan 26 jawaban dengan kategori yang sangat valid dan lima jawaban kategori valid. Secara keseluruhan, jika dipersentasekan diperoleh hasil 84.5\%. Kepada ahli materi terdapat 14 pernyataan yang sangat valid dan tiga pernyataan valid. Ahli materi memberikan skor sebanyak 72 dari Jumlah skor maksimal adalah 85. Secara keseluruhan, jika dipersentasekan diperoleh hasil $84.7 \%$. Jumlah pernyataan yang diberikan kepada ahli pembelejaran sejumlah 24 butir. Terdapat 23 pernyataan yang sangat valid dan satu pernyataan valid. Ahli pembelajaran memberikan skor 111 dari jumlah skor maksimal adalah 120 . Secara keseluruhan jika diprosenstasekan diperoleh hasil $92.5 \%$. Namun, media SIPERDA yang dikembangkan juga masih tetap direvisi berdasarkan saran ahli, sehingga media yang dikembangkan semakin baik dan memiliki kualitas tinggi. Meskipun diterapkan pada mata pelajaran berbeda, hasil penelitian ini sejalan dengan penelitian terdahulu skor dari mengembangkan media augmented reality pada mata pelajaran matematika yaitu ahli media, ahli materi, ahli pembelajaran secara berturut-turut yaitu $89.2 \%, 86.1 \%$ dan 87,5\% dengan rata-rata keseluruhan 87.6\% (Bagus, Buchori, \& Aini, 2018).

Kepraktisan pada penelitian diperoleh dengan memberikan angket respons kepada empat siswa skala kecil dan 18 siswa kelas eksperimen. Jumlah pernyataan yang diberikan kepada siswa sejumlah 21 butir. Temuan yang didapatkan pada penelitian ini setelah dilakukan pemberian angket dari skala kecil sebanyak 12 pernyataan dijawab "YA" oleh empat siswa, delapan pernyataan dijawab "YA" oleh tiga siswa, dan satu pernyataan dijawab "YA" oleh 2 siswa. Hasil jawaban yang diberikan siswa yaitu menunjukkan siswa banyak yang sepakat dengan pernyataan dan hanya satu pernyataan dijawab oleh dua siswa berkaitan dengan bagaimana siswa dapat menampilkan gambar tiga Dimensi. Jika diprosentasekan hasil dari uji skala kecil memperoleh nilai 88\%. Sedangkan dari skala besar Temuan yang didapatkan pada penelitian ini setelah dilakukan pemberian angket dari skala kecil sebanyak empat pernyataan dijawab "YA" oleh 14 siswa, dua pernyataan dijawab "YA" oleh 13 siswa, lima pernyataan dijawab "YA" oleh 12 siswa, empat pernyataan dijawab "YA" oleh 11 siswa, tiga pernyataan dijawab "YA" oleh 10 siswa dan tiga pernyataan dijawab "YA" oleh sembilan siswa. Hasil jawaban yang diberikan siswa sebagian besar sepakat dengan pernyataan yang ada pada angket baik secara skala kecil maupun besar. Jika diprosentasekan hasil dari uji skala kecil memperoleh nilai $82.5 \%$. Keseluruhan respons siswa menujukkan hasil dan respons yang baik. Meskipun diterapkan di tingkat kelas berbeda, penelitian terdahulu siswa selalu menujukkan ketertarikan, semangat dan respons yang baik terkait penerapan perangkat IPA (Listyawati, 2012). 
Selain angket respons media diberikan kepada siswa, angket kepraktisan juga diberikan kepada guru. Guru mendapat angket yang memiliki 11 pernyataan. Guru sebagai observer pada uji coba skala kecil memberikan jawaban dengan kategori sangat valid berjumlah empat pernyataan dan valid berjumlah tujuh pernyataan. Jika dipersentasekan hasil dari uji skala kecil memperoleh nilai $87.2 \%$. Artinya, lebih dari $50 \%$ pernyataan yang ada terkait media membantu guru dalam menjelaskan materi kepada siswa. Guru sebagai observer pada uji coba skala besar memberikan jawaban dengan kategori sangat valid berjumlah delapan pernyataan dan valid berjumlah tiga pernyataan. Jika dipersentasekan hasil dari uji skala kecil memperoleh nilai $92.5 \%$. Hasil jawaban yang diberikan guru sebagian besar sepakat dengan pernyataan yang ada pada angket baik secara skala kecil maupun besar. Akan tetapi, guru tetap memberikan masukan di setiap pernyataan dalam angket agar media layak digunakan siswa. Hal ini sejalan dengan penelitian terdahulu, meskipun media IPA dibuat dengan wujud berbeda, media akan memudahkan guru dalam menyampaikan materi (Vikagustanti, Sudarmin, \& Pamelasari, 2014).

Analisis posttest yang diberikan pada 14 siswa memiliki hasil rata-rata nilai pada kelas Ocean sebesar 83. Soal yang berjumlah 18 diberikan siswa dan sebanyak enam siswa mendapatkan skor $\leq 75$. Hasil jawaban siswa ini terlihat bahwa masih sedikit siswa yang memahami IPA dengan baik. Masih banyak siswa yang salah pada soal nomor 4 dimana diminta menunjukkan tentang organ sistem peredaran darah manusia. Hal ini dilihat dari berbagai ragam jawaban yang diberikan oleh siswa. Berdasarkan data hasil belajar siswa di kelas Ocean tanpa menggunakan media masih belum begitu baik. Meskipun berbeda sasaran hasil, penelitian terdahulu juga menunjukkan bahwa hasil belajar IPA tentang sistem peredaran darah tergolong rendah (Fajar, 2016).

Data pada kelas Island memiliki skor yang lebih tinggi sebesar 89. Hasil jawaban siswa menunjukkan adanya kenaikan setelah siswa mengikuti pembelajaran menggunakan media SIPERDA. Soal yang berjumlah 18 dimana awalnya siswa hanya mampu menjawab sekitar 50\% dari soal, setelah diberi perlakuan media SIPERDA hasil belajar meningkat menjadi $>75$. Siswa yang awalnya bingung menjawab soal di nomor 4 tentang organ peredaran darah manusia, setelah mempelajari menggunakan media SIPERDA siswa dapat menjawab dengan benar. Jadi, dapat disimpulkan bahwa media SIPERDA dilengkapi augmented reality dapat memengaruhi hasil belajar siswa. Meskipun penelitian terdahulu dengan materi berbeda, tetapi menunjukkan hasil bahwa media dilengkapi augmented reality mampu meningkatkan hasil belajar siswa (Harley, Poitras, Jarrell, Duffy, \& Lajoie, 2016), (Karagozlu, 2018), (Chen, Huang, \& Chou, 2019).

\section{SIMPULAN}

Penelitian ini menghasilkan media SIPERDA dilengkapi augmented reality yang memiliki kriteria valid, praktis, dan efektif. Implementasi untuk melihat ketiga kriteria dengan menjadikan siswa dan guru sebagai subjek baik secara skala kecil maupun skala besar. Berdasarkan penelitian dan pengembangan media SIPERDA menggunakan model ADDIE menurut Nieveen media berkualitas apabila sudah diuji melalui kevalidan, kepraktisan dan keefektifan. Berdasarkan pernyataan diatas dapat dijabarkan untuk kevalidan memiliki rerata 87.2\%, kepraktisan 88\% dan keefektifan sebesar $0.026<0.05$ melalui uji ancova. Maka dari itu dapat disimpulkan bahwa media SIPERDA efektif, valid dan praktis digunakan sebagai variasi sumber belajar mata pelajaran IPA khusunya materi sistem peredaran darah hewan dan manusia.

Berdasarkan hasil pengembangan dan penelitian tentang media SIPERDA, pengembang dapat memberikan saran yaitu sebagai berikut kepada guru sebelum kegiatan pembelajaran menggunakan media SIPERDA guru wajib memastikan keadaan komputer atau laptop yang akan digunakan agar saat pembelajaran meminimalisir banyak hal yang tidak diinginkan. Saran untuk sekolah sekolah diharapkan membantu para guru menyediakan segala kebutuhan yang berkaitan dengan variasi dan pemanfaatan media SIPERDA untuk pembelajaran. Untuk pengembang lainnya agar memilih sasaran materi yang belum pernah dibuat dan perlu mempertimbangkan sekolah dengan fasilitas yang mumpuni. Hal ini dimaksudkan agar media yang tercipta dapat dimanfaatkan dan digunakan sebagai variasi dalam pembelajaran di zaman yang serba canggih.

\section{DAFTAR RUJUKAN}

Ardini, P. P. (2012). Pengaruh Dongeng dan Komunikasi terhadap Perkembangan Moral Anak Usia 7-8 Tahun. Jurnal Pendidikan Anak, 1(2), 44-58.

Astutik, L. S. (2019). Pengaruh Media Laron (Gamelan Saron) dengan Lagu Daerah terhadap Hasil Belajar untuk Anak. Jurnal Pemikiran dan Pengembangan Sekolah Dasar, 7(4), 23-29.

Astutik, W. (2016). Pengembangan Permainan Kuartet sebagai Media Pembelajaran Materi Klasifikasi Makhluk Hidup Kelas Vii Smp. Pensa: Jurnal Pendidikan Sains, 4(03), 1-5.

Bagus, K. H., Buchori, A., \& Aini, A. N. (2018). Pengembangan Media Pembelajaran Berbasis Android menggunakan Augmented Reality pada Materi Bangun Ruang Sisi Datar. Jurnal Pendidikan Matematika dan Sains, VI(1), 61-69.

Baharun, H. (2015). Penerapan Pembelajaran Active Learning untuk Meningkatkan Hasil Belajar Siswa di Madrasah. Jurnal Pendidikan Pedagogik, 1(1), 39.

Cakir, R., \& Korkmaz, O. (2019). The Effectiveness of Augmented Reality Environments on Individuals with Special Education Needs. Education and Information Technologies, 24(2), 1631-1659. https://doi.org/10.1007/s10639-018-9848- 
Chen, C. H., Huang, C. Y., \& Chou, Y. Y. (2019). Effects of Augmented Reality-Based Multidimensional Concept Maps on Students' Learning Achievement, Motivation And Acceptance. Universal Access in the Information Society, 18(2), 257268. https://doi.org/10.1007/s10209-017-0595-z

Cheng, K. (2018). Parents' User Experiences of Augmented Reality Book Reading: Perceptions, Expectations, and Intentions. Educational Technology Research and Development, (1). https://doi.org/10.1007/s11423-018-9611-0

Chiang, T. H. C., Yang, S. J. H., \& Hwang, G. J. (2014). An Augmented Reality-based Mobile Learning System to Improve Students' Learning Achievements and Motivations in Natural Science Inquiry Activities. Educational Technology \& Society, 17(4), 352-365.

Fajar, N. (2016). Proses Pembelajaran Biologi pada Materi Sistem Peredaran Darah Manusia di Kelas VIII SMP Negeri 3 Rambatan. Ta'dib, 19(2), 103. https://doi.org/10.31958/jt.v19i2.466

Falahudin, I. (2014). Pemanfaatan Media dalam Pembelajaran. Lingkar Widyawiswara, 1(4), 104-117.

Gagne, R. (1984). Learning Outcomes and their Effects. The American Psychologist, 39(4), 377-385.

Gonydjaja, R., \& Mayongga, Y. (2014). Aplikasi Museum Zoologi Berbasis Augmented Reality. 8(1), 331-334.

Harden, R. M. (2002). Learning Outcomes and Instructional Objectives: Is There a Difference? Medical Teacher, 24(2), 151155. https://doi.org/10.1080/0142159022020687

Harley, J. M., Poitras, E. G., Jarrell, A., Duffy, M. C., \& Lajoie, S. P. (2016). Comparing Virtual and Location-Based Augmented Reality Mobile Learning: Emotions and Learning Outcomes. Educational Technology Research and Development, 64(3), 359-388. https://doi.org/10.1007/s11423-015-9420-7

Juniati, N. W., \& Widiana, I. W. (2017). Penerapan Model Pembelajaran Inkuiri untuk Meningkatkan Hasil Belajar IPA. Journal of Education Action Research, 1(2), 122. https://doi.org/10.23887/jear.v1i2.12045

Karagozlu, D. (2018). Determination of the Impact of Augmented Reality Application on the Success and Problem-Solving Skills of Students. Quality and Quantity, 52(5), 2393-2402. https://doi.org/10.1007/s11135-017-0674-5

Khan, T., Johnston, K., \& Ophoff, J. (2019). The Impact of an Augmented Reality Application on Learning Motivation of Students. Advances in Human-Computer Interaction, 2019. https://doi.org/10.1155/2019/7208494

Khotimah, K., \& Ardian, Y. (2017). Aplikasi Media Pembelajaran Ilmu Pengetahuan Alam (IPA) dengan Teknologi Augmented Reality (Studi Kasus: Kelas IV SDN Sukun 2 Malang). Fakultas Teknologi Informasi, 1(5), 1-6.

Laine, T. H., Nygren, E., \& Dirin, A. (2016). Science Spots AR : A Platform for Science Learning Games with Augmented Reality. Educational Technology Research and Development, 64(3), 507-531. https://doi.org/10.1007/s11423-015-9419-0

Liarokapis, F., Mourkoussis, N., White, M., Darcy, J., Sifniotis, M., Petridis, P., .. Lister, P. F. (2004). Web3D and Augmented Reality to Support Engineering Education Fotis. World Transactions on Engineering and Technology Education, 3(1), 11-14. https://doi.org/10.1521/ijgp.55.1.87.56558

Liberati, N. (2016). Augmented Reality and Ubiquitous Computing: The Hidden Potentialities of Augmented Reality. AI and Society, 31(1), 17-28. https://doi.org/10.1007/s00146-014-0543-x

Listyawati, M. (2012). Pengembangan Perangkat Pembelajaran IPA Terpadu d SMP. Journal of Innovative Science Education, $1(1), 61-69$.

Mappeasse, M. Y. (2009). Pengaruh Cara dan Motivasi Belajar terhadap Hasil Belajar Programmable Logic Controller (PLC) Siswa Kelas III Jurusan Listrik SMK Negeri 5 Makassar. Jurnal Medtek, 1(2), 1-6.

Papanastasiou, G., Drigas, A., Skianis, C., Lytras, M., \& Papanastasiou, E. (2019). Virtual and Augmented Reality Effects on K-12, Higher and Tertiary Education Students' Twenty-First Century Skills. Virtual Reality, 23(4), 425-436. https://doi.org/10.1007/S10055-018-0363-2

Pellas, N., Fotaris, P., Kazanidis, I., \& Wells, D. (2018). Augmenting The Learning Experience in Primary and Secondary School Education: A Systematic Review of Recent Trends In Augmented Reality Game-Based Learning. Virtual Reality, (0123456789), 1-18. https://doi.org/10.1007/s10055-018-0347-2

Saputri, F. E., Annisa, M., \& Kusnandi, D. (2018). Pengembangan Media Pembelajaran IPA menggunakan Augmented Reality (AR) Berbasis Android Pada Siswa Kelas III SDN 015 Tarakan. Widyagogik: Jurnal Pendidikan dan Pembelajaran Sekolah Dasar, 6(1), 57-72.

Sartika, Y., Tambunan, T. D., \& Telnoni, P. A. (2016). Aplikasi Pembelajaran Tata Surya untuk IPA Kelas 6 Sekolah Dasar menggunakan Augmented Reality Berbasis Android. e-Proceeding of Applied Science, 2(3), 895-908.

So, W. W. M., Chen, Y., \& Wan, Z. H. (2019). Multimedia e-Learning and Self-Regulated Science Learning: A Study of Primary School Learners' Experiences and Perceptions. Journal of Science Education and Technology, $28(5), 508-522$. https://doi.org/10.1007/s10956-019-09782-y

Subekti, A. (2017). Tema 4 Sehat Itu Penting Buku Tematik Terpadu Kurikulum 2013: Buku Siswa SD/MI Kelas V. Pusat Kurikulum dan Perbukuan Kemendikbud.

Syukri, R., Winarni, S., \& Hidayat, R. (2018). Pengembangan Media Pembelajaran Komik Matematika Berbasis Problem Based Learning dengan Manga Studio V05 dan Geogebra. EDUMATICA: Jurnal Pendidikan Matematika, 8(2), 81-91. https://doi.org/10.22437/edumatica.v8i2.5486

Tambayong, M. O., Lumenta, A. S., \& Sugiarso, B. A. (2016). Implementasi Augmented Reality pada Sistem Sirkulasi Darah Manusia. E-Journal Teknik Elektro dan Komputer, 5(3), 49-57. 
1819 Jurnal Pendidikan, Vol. 5, No. 12, Bln Desember, Thn 2020, Hal 1812-1819

Tarng, W., Lin, Y. S., Lin, C. P., \& Ou, K. L. (2016). Development of a Lunar-Phase Observation System Based on Augmented Reality and Mobile Learning Technologies. Mobile Information Systems, 2016(3), 1-12. https://doi.org/10.1155/2016/8352791

Vikagustanti, D. A., Sudarmin, \& Pamelasari, S. D. (2014). Pengembangan Media Pembelajaran Monopoli IPA Tema Organisasi Kehidupan sebagai Sumber Belajar untuk Siswa SMP. Unnes Science Education Journal, 3(2), 468-475.

Yoon, S., Anderson, E., Lin, J., \& Elinich, K. (2017). How Augmented Reality Enables Conceptual Understanding of Challenging Science Content. Educational Technology and Society, 20(1), 156-168. 